\title{
MORTALITY RISK OF COLORECTAL CANCER IN BRAZIL FROM 1980 TO 2013
}

\author{
Ronaldo Coimbra OLIVEIRA ${ }^{1}$ and Marco Antônio Vasconcelos RÊGO²
}

Received 8/1/2016

Accepted 15/2/2016

\begin{abstract}
Background - Colorectal cancer is one of the most common cancer worldwide, and variation in its mortality rates indicates the importance of environmental factors in its occurrence. While trend studies have indicated a reduction in colorectal cancer mortality rates in most developed countries, the same trends have not been observed in developing countries. Moreover, trends may differ when analyzed by age and sex. Objective - The present study aimed to analyze the trends in risk of colorectal cancer death in Brazil based on sex and age group. Methods - Death records were obtained from the Mortality Information System of the Ministry of Health. The risk of death and the average annual percent changes (AAPC) in the mortality rates were estimated using joinpoint analysis of long-term trends from 1980 to 2013. All of the statistical tests were two-sided and had a significance level of 5\%. Results - Colorectal cancer mortality rates were found to have increased in the last 15 years for both sexes and for all age ranges. The rate ratio (RR) was statistically higher at ages 70 to 79 for men (RR: $1.37 ; 95 \%$ CI: $1.26 ; 1.49)$ compared to women (RR: 1.14 $95 \%$ CI: 1.06; 1.24). Increases in AAPC were observed in both sexes. Although men presented higher percent changes (AAPC: 1.8; $95 \%$ CI: $1.1 ; 2.6$ ) compared to women (AAPC: $1.2 ; 95 \%$ CI: $0.4 ; 2.0$ ), this difference was not statistically significant. Growth trends in mortality rates occurred in all age groups except for in women over 70. Conclusion - Unlike Europe and the US, Brazil has shown increases in death rates due to colorectal cancer in the last three decades; however, more favorable trends were observed in women over 70 years old. The promotion of healthier lifestyles in addition to early diagnosis and improved treatment should guide the public health policies targeting reductions in colorectal cancer.

HEADINGS - Colorectal neoplasms, mortality. Time series studies. Population surveillance. Age distribution. Developing countries. Public health policy.
\end{abstract}

\section{INTRODUCTION}

In recent decades, cancer has emerged as a leading cause of death in both developed countries and those under development. In 2012, global statistics revealed that cancer was responsible for approximately 8.2 million deaths, $65 \%$ of which occurred in developing countries. Colorectal cancer (CRC) was the third most frequent among men and the second most common among women, accounting for 694,000 deaths in both sexes ${ }^{(15)}$. In the same year, there were 184,073 cancer deaths in Brazil, approximately $8.0 \%$ (14,612 deaths) of which were related to $\mathrm{CRC}$, resulting in CRC being one of the top five causes of death in both men and women ${ }^{(14)}$.

Variations in the incidence and mortality rates of CRC indicate the importance of environmental factors in the occurrence of CRC and the potential to prevent CRC diagnoses ${ }^{(11)}$. Age and history of adenomatous polyps or inflammatory bowel disease are the primary nonmodifiable factors related to CRC, whereas alcohol and tobacco use, a sedentary lifestyle and eating habits are some of the major etiological factors in its incidence ${ }^{(5,12)}$.

Trend studies conducted worldwide have indicated a reduction in CRC mortality rates in most developed countries; however, in developing countries, this same trend has not been observed. Moreover, when the trends were analyzed by age and sex, different patterns were observed ${ }^{(1,2,24,25)}$.

Reduction in mortality is one of the main objectives of interventions based on screening and treatment; therefore, studies can be useful in evaluating the policies and programs aimed at monitoring cancer care as well as the changes in outcomes due to population lifestyle, environmental risks and the effectiveness of the health care system ${ }^{(25)}$. The present study aimed to analyze the trends in risk of CRC death in Brazil based on sex and age group.

\section{METHODS}

This is an ecological study that used the Mortality Information System (SIM) of the Department of Informatics (DATASUS) of the Ministry of Health ${ }^{(17)}$. From the SIM, we obtained data on CRC deaths from 1980 to 2013. The population count (1996), censuses (1980, 1991 and 2000) and estimates of the resident population (other years) were obtained from the Brazilian Institute of Geography and Statistics (IBGE) ${ }^{(13)}$. To evaluate the quality of the data on CRC deaths and the SIM coverage,

${ }^{1}$ Hospital Universitário Professor Alberto Antunes, Universidade Federal de Alagoas, Maceió, AL, Brasil; ${ }^{2}$ Faculdade de Medicina da Bahia, Universidade Federal da Bahia, Salvador, BA, Brasil.

Correspondence: Ronaldo Coimbra de Oliveira. Hospital Universitário Professor Alberto Antunes, Universidade Federal de Alagoas. Av. Lourival Melo Mota, s/n. Cidade Universitária - CEP: 57072-900 - Maceió, AL, Brasil. E-mail: ronaldo.oliveira@ebserh.gov.br 
the proportion of ill-defined conditions (Chapter XVI and XVIII), the proportion of malignant neoplasms of other digestive organs and ill-defined sites in the digestive tract (159 and C26) and the proportion of malignant neoplasm without specification of site (C80 and 199) were analyzed. Deaths that had no corresponding information on age, gender and place of residence were excluded.

The risk of death due to CRC was estimated using mortality rates expressed by sex and age group; age was divided into six groups (less than 40 years, 40 to 49 years old, 50 to 59 years old, 60 to 69 years old, 70 to 79 years and 80 and over). The analyzed data included the CRC deaths coded 153-154 from 1980 to 1995 , according to the International Classification of Diseases (ICD) 9th Review ${ }^{(20)}$, in addition to the deaths coded C18 to C21 based on the ICD 10th Review for the years 1996 to $2013^{(21)}$.

To minimize the instability of the number of deaths in the extracts and possible random fluctuations between years, analyses were performed by using aggregate moving averages of three-year periods, such as 1980/81/82, $1981 / 1982 / 1983$, and so on. Therefore, the referenced years represented the mean of 3 years. In addition, to compare mortality throughout the period and to neutralize the effect of the different age distributions of the populations, rates were standardized by age and sex in each extract using the direct method and the standard world population recommended by the International Agency for Research on Cancer/ World Health Organization (IARC / WHO) ${ }^{(6)}$.

Standardized mortality ratios were used to verify the difference between the risk of death by sex and age group.

The temporal trends of mortality were determined using Joinpoint Regression Analysis Program, version 4.2.0.1, National Cancer Institute, Maryland, United States of America, which enables the computation and analysis of the rate trends in segments, thus providing models that summarize outcomes over time. These trends are described by the Annual Percent Change (APC) and the Average Annual Percent Change (AAPC), which quantifies the variation in rates by year and the average trends over a period of multiple years, respectively ${ }^{(16,18)}$. The specifications used in the program were the model: $\log (\mathrm{y})=\mathrm{bx}$, where $Y$ was the adjusted mortality rate due to CRC and $\mathrm{X}$ was the year of the occurrence of death. We assumed a nonconstant variance, using the maximum of five joinpoints. The determination method was Grid Search (GS) and the model selection method used was the permutation test. In describing trends, the terms increase and decrease were used when the slope of a trend was statistically significant. For nonstatistically significant trends, terms such as stable, no significant increase and no significant decrease were used. The software Epidat version 4.1 was used to calculate the rates and their $95 \%$ confidence intervals ${ }^{(9)}$.

The data used in this study were public and available on the Internet at DATASUS and did not identify individuals. Therefore, there was no need for the project to be evaluated by a Research Ethics Committee.

\section{RESULTS}

A significant improvement in the quality of the SIM data for both sexes and age groups was observed throughout the entire study period. In 2013, deaths from ill-defined causes accounted for $5.9 \%$ (CI95\%: $5.8 ; 6.0)$ of the total number of registered deaths, while ill-defined cancers represented 5.6\% (CI95\%: 5.4; 5.8) of the total number of neoplasm deaths, and unspecified causes represented 3.2\% (CI95\%: $3.1 ; 3.3$ ) of the deaths registered under digestive tract neoplasms (Figure 1). Of the ill-defined digestive tract neoplasms, women had a higher proportion $(6.6 \% \mathrm{CI} 95 \%$ : 6.6; 6.9) than the men $(4.9 \%$ CI95\%: $4.7 ; 5.1)$. This difference was more pronounced in the 40- to 79-year-old participants. There was no difference between the sexes in relation to the other indicators when all of the age groups were considered. However, when age was considered, women showed a higher proportion of deaths without specification when they were over 70 years old. On the other hand, men showed higher proportions of ill-defined causes than women in the 40- to 79-year-old age range (data not shown).

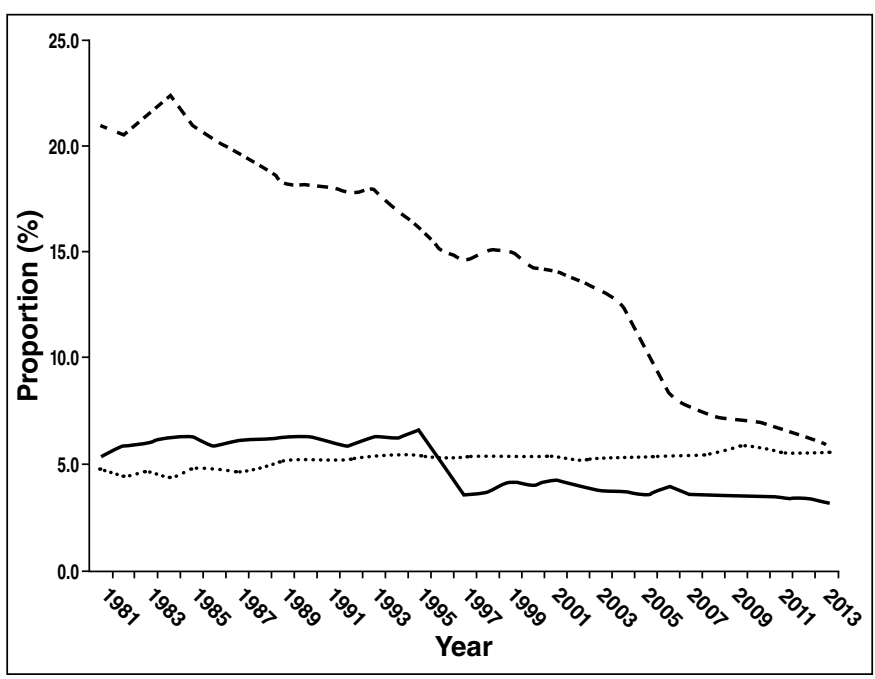

FIGURE 1. Ill-defined causes, ill-defined malignant neoplasms at digestive organs and malignant neoplasms without specification site at Brazil from 1981 a 2012

From 1981 to 1996 , the CRC mortality rates ranged from 2.79 (CI95\%: $2.70 ; 2.80)$ to 3.93 (CI95\%: $3.83,3.9)$ per 100,000 person-year, and from 1997 to 2012, the variation was from 4.11 (CI95\%: 4.01; 4.11) to 7.57 (CI95\%: 7.44; 7.57) per 100,000 person-year. The increased risk of death during the 1981 to 1996 period and the 1997 to 2012 period was $41 \%(\mathrm{CI} 95 \%: 35.0 ; 47.0)$ and $84.0 \%$ (CI95\%: 79.0; 90.0), respectively (data not shown). There was a significant difference in risk based on sex between 1997 and 2012, when men had a higher risk of death (RR: 1.93; CI95\%: 1.85; 2.01) than women (RR: 1.77 ; CI95\%: 1.70; 1.84) (data not shown). 
The mortality rates of CRC increased with increasing age for both sexes during the analyzed period $(P<0.001)$. During the period from 1981 to 1996 , there was a significant increase in risk for women below 40 years old with a ratio rate of 1.51 (CI95\%: 1.19; 1.92), while in men, the increased risk was significant for those who were 60 to 69 years old (ratio rate: $1.22 ; 95 \%$ CI: $1: 08 ; 1: 38$ ) and 70 to 79 years old (ratio rate: $1.19 ; 95 \%$ CI: $1.05 ; 1.35$ ). From 1997 to 2012, there was an increased risk of death for both sexes in all age groups (Table 1). In 1981, there was no significant difference in risk of death between the sexes for any age group. In 1996, the risk was only lower for men who were aged 80 years or older (rate ratio: $0.86 ; 95 \%$ CI: $0.76 ; 0.98$ ). However, this trend was reversed in 2012, when men over 60 years of age had a higher risk of death (Figure 2).

The AAPC between 1981 and 2012 showed a significant growing trend in the risk of death in all of the age groups and for both sexes; this trend was maintained for men and women, except for the women over 70 years of age, whose risk of death remained stable over the same time period (Figure 3). The trends of the age-adjusted mortality rates for men significantly increased from 1986 to 2002 (APC: 2.3; $95 \%$ CI: $2.0 ; 2.6$ ) and from 2008 to 2012 (APC: $3.6 ; 95 \%$ CI: $1.9 ; 4.7)$, whereas in women, the growth was only significant from 1988 to 2006 (APC: 2.2; 95\% CI: 1.8; 2.5) (Figure 4).
Men below 40 years of age exhibited an increasing trend in mortality risk from 1981 to 2012; this trend was more pronounced between 1992 and 2012, with an APC of $1.8 \%$ (95\% CI: $1.6 ; 2.0)$. Women only had an increasing trend from 1981 to 1987 and from 1991 to 2006; during the other years, the trend in mortality risk remained constant. For the 40- to 49-year-old age group, men showed an annual increasing trend of $1.7 \%$ (95\% CI: $1.4 ; 2.0)$ starting in 1994, whereas the women had a significant annual growth of $1.9 \%(95 \%$ CI: $1.6 ; 2.3)$ starting in 1995 . A similar growing trend of $3.3 \%(95 \%$ CI: $2.2 ; 4.4)$ was observed for men and women in the 50- to 50-year-old age group from 2008 to 2012. Men aged from 60 to 69 years had an annual growth of $2.4 \%(95 \% \mathrm{CI}: 2.3 ; 2.5)$ starting in 1984 , while women in the same age group had an annual growth of $6.6 \%$ (95\% CI: $1.2 ; 12.4)$ from 2010 to 2012 . Of the individuals between 70 and 79 years old, men had a significantly increasing mortality risk from 1990 to 2005 only (APC: $2.9 ; 95 \%$ CI: $2.5 ; 3.4$ ); a similar trend was observed for women from 1987 to 2005 (APC: $1.9 ; 95 \%$ CI: $1.5 ; 2.3)$. Men aged over 80 years showed a significant increasing trend throughout all of the study years except for the period from 2005 to 2008 . However, a different pattern was observed among women of the same age group; there was only significant growth in the period from 1981 to 2001 (Figure 5).

TABLE 1. Colorectal Cancer mortality crude rate and ratio by gender and age range. Brazil from 1981 to 2012

\begin{tabular}{|c|c|c|c|c|c|c|}
\hline \multirow{2}{*}{$\begin{array}{l}\text { Brazil. Regions by } \\
\text { age (years) }\end{array}$} & \multicolumn{4}{|c|}{ Mortality rate* } & \multicolumn{2}{|c|}{ Mortality rate ratio $(95 \% \mathrm{IC})$} \\
\hline & 1981 & 1996 & 1997 & 2012 & 1981-1996 & $1997-2012$ \\
\hline Under 40 & 0.25 & 0.34 & 0.35 & 0.44 & $1.35(1.15 ; 1.59)^{\#}$ & $1.25(1.10 ; 1.42)^{\#}$ \\
\hline $40-49$ & 3.11 & 3.44 & 3.72 & 4.93 & $1.11(0.97 ; 1.27)$ & $1.33(1.20 ; 1.46)^{\#}$ \\
\hline $50-59$ & 8.33 & 8.72 & 8.92 & 13.67 & $1.05(0.94 ; 1.16)$ & $1.53(1.42 ; 1.65)^{\#}$ \\
\hline \multirow[t]{2}{*}{80 and more } & 70.00 & 72.85 & 76.36 & 105.44 & $1.04(0.93 ; 1.16)$ & $1.38(1.29 ; 1.48)^{\#}$ \\
\hline & $* * P<0.001$ & $* * P<0.001$ & $* * P<0.001$ & $* * P<0.001$ & & \\
\hline \multicolumn{7}{|l|}{ Male } \\
\hline Under 40 & 0.27 & 0.33 & 0.33 & 0.42 & $1.22(0.97 ; 1.54)$ & $1.28(1.06 ; 1.54)^{\#}$ \\
\hline $40-49$ & 3.00 & 3.23 & 3.53 & 4.58 & $1.08(0.89 ; 1.32)$ & $1.30(1.13 ; 1.50)^{\#}$ \\
\hline $50-59$ & 7.84 & 8.98 & 8.98 & 14.10 & $1.14(0.99 ; 1.33)$ & $1.57(1.40 ; 1.75)^{\#}$ \\
\hline \multicolumn{7}{|l|}{ Female } \\
\hline Under 40 & 0.23 & 0.35 & 0.36 & 0.45 & $1.51(1.19 ; 1.92)^{\#}$ & $1.23(1.02 ; 1.47)^{\#}$ \\
\hline $40-49$ & 3.21 & 3.64 & 3.91 & 5.26 & $1.13(0.94 ; 1.37)$ & $1.35(1.18 ; 1.54)^{\#}$ \\
\hline $50-59$ & 8.80 & 8.46 & 8.85 & 13.31 & $0.96(0.83 ; 1.11)$ & $1.50(1.36 ; 1.67)^{\#}$ \\
\hline $60-69$ & 18.67 & 20.30 & 21.31 & 26.41 & $1.09(0.97 ; 1.22)$ & $1.24(1.14 ; 1.35)^{\#}$ \\
\hline $70-79$ & 39.80 & 43.48 & 44.82 & 51.26 & $1.09(0.98 ; 1.22)$ & $1.14(1.06 ; 1.24) \#$ \\
\hline \multirow[t]{2}{*}{80 and more } & 72.79 & 77.10 & 80.60 & 101.41 & $1.06(0.92 ; 1.22)$ & $1.26(1.15 ; 1.37)^{\#}$ \\
\hline & $* * P<0.001$ & $* * P<0.001$ & $* * P<0.001$ & $* * P<0.001$ & & \\
\hline
\end{tabular}

Source: Information System on Mortality - SIM/ Ministry of Health.

* Mortality rate by 100,000 person-years. ** $c^{2}$ for trends. " Mortality ratio significant at level $P<0.05$. 


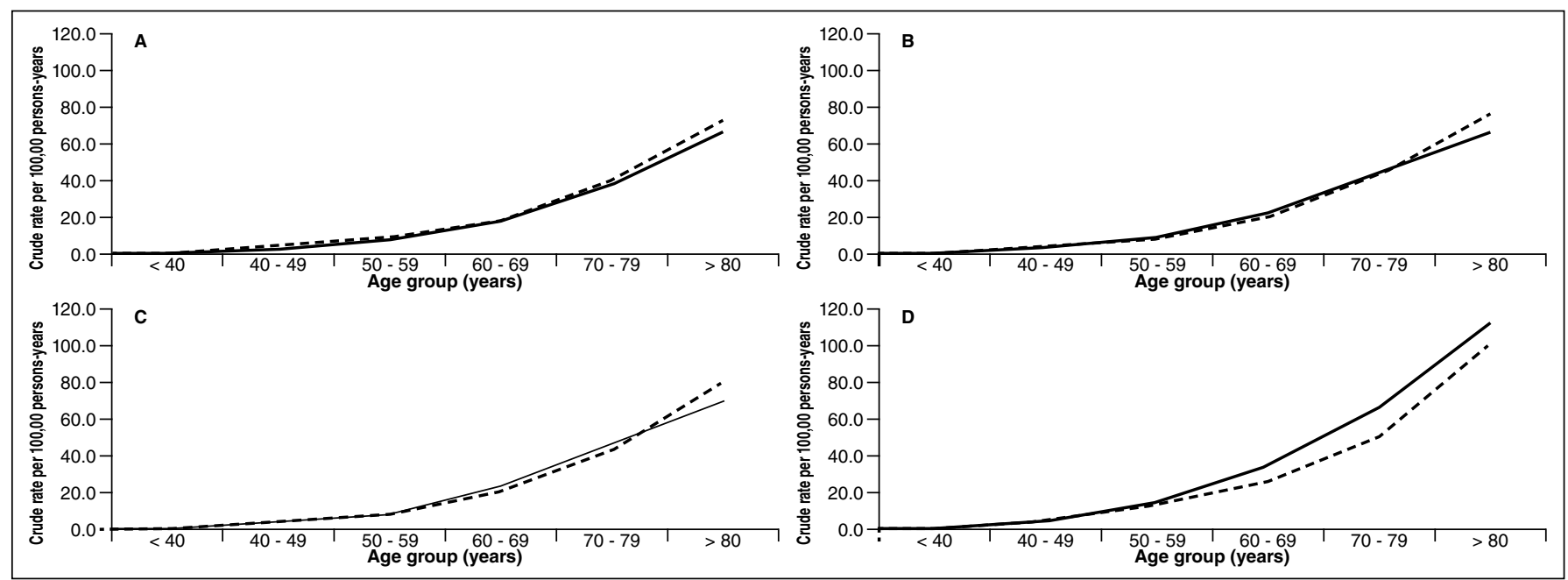

FIGURE 2. Crude rate colorectal cancer mortality per 100,000 person - years for Brazil at 1981, 1996, 1997 and 2012.

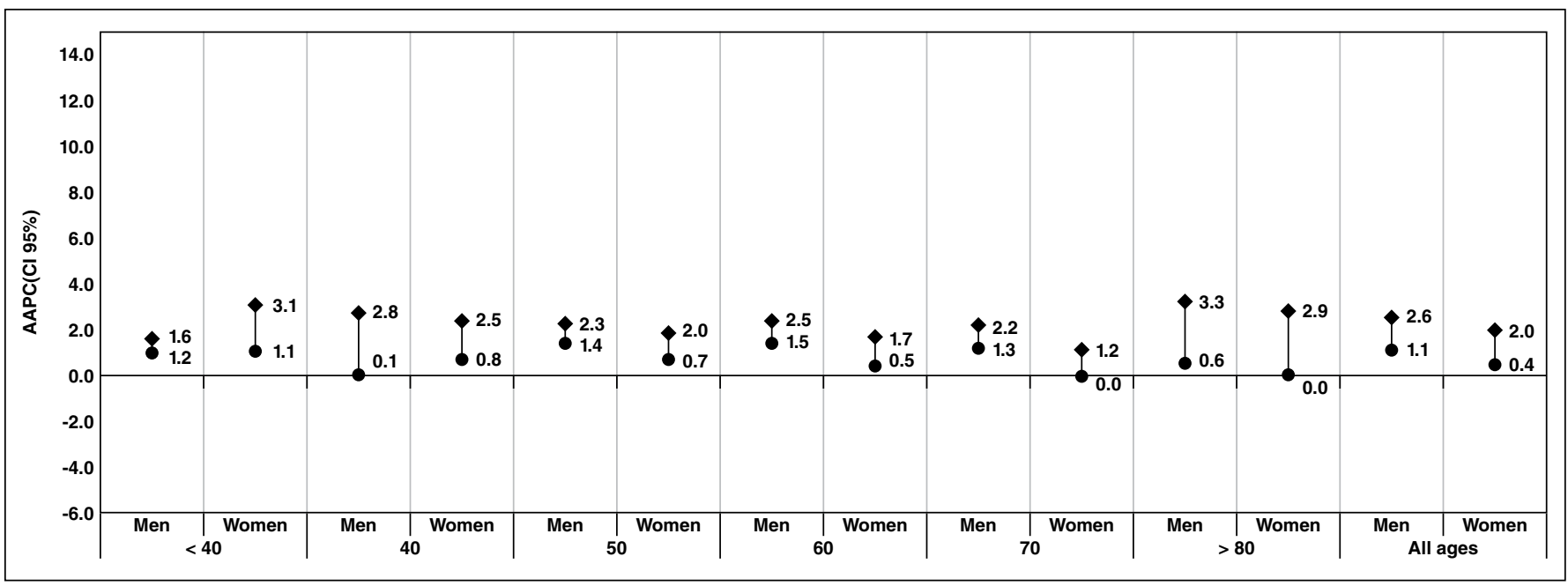

FIGURE 3. Comparative of Average Annual Percent Change (AAPC) from colorectal cancer mortality rate according age ranging and gender at Brazil between 1981-2012.

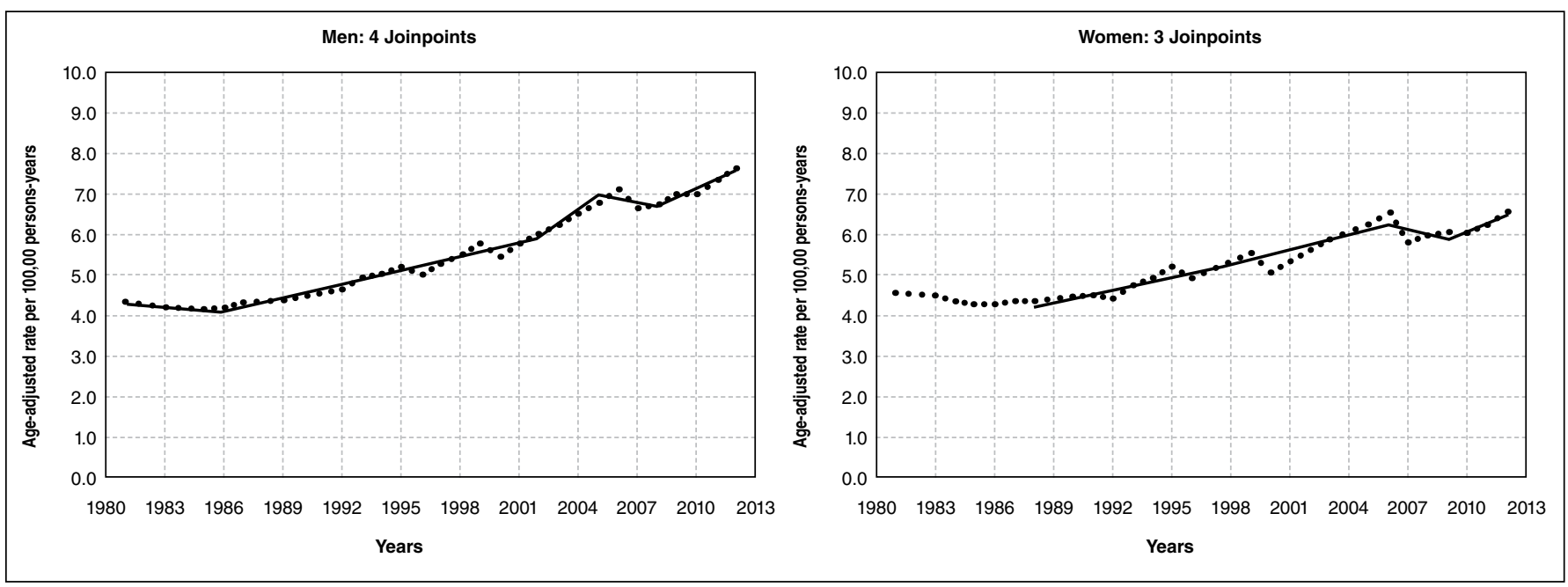

FIGURE 4. Age-adjusted colorectal cancer mortality rate per 100,000 person - years for Brazil from 1981 to 2012. 

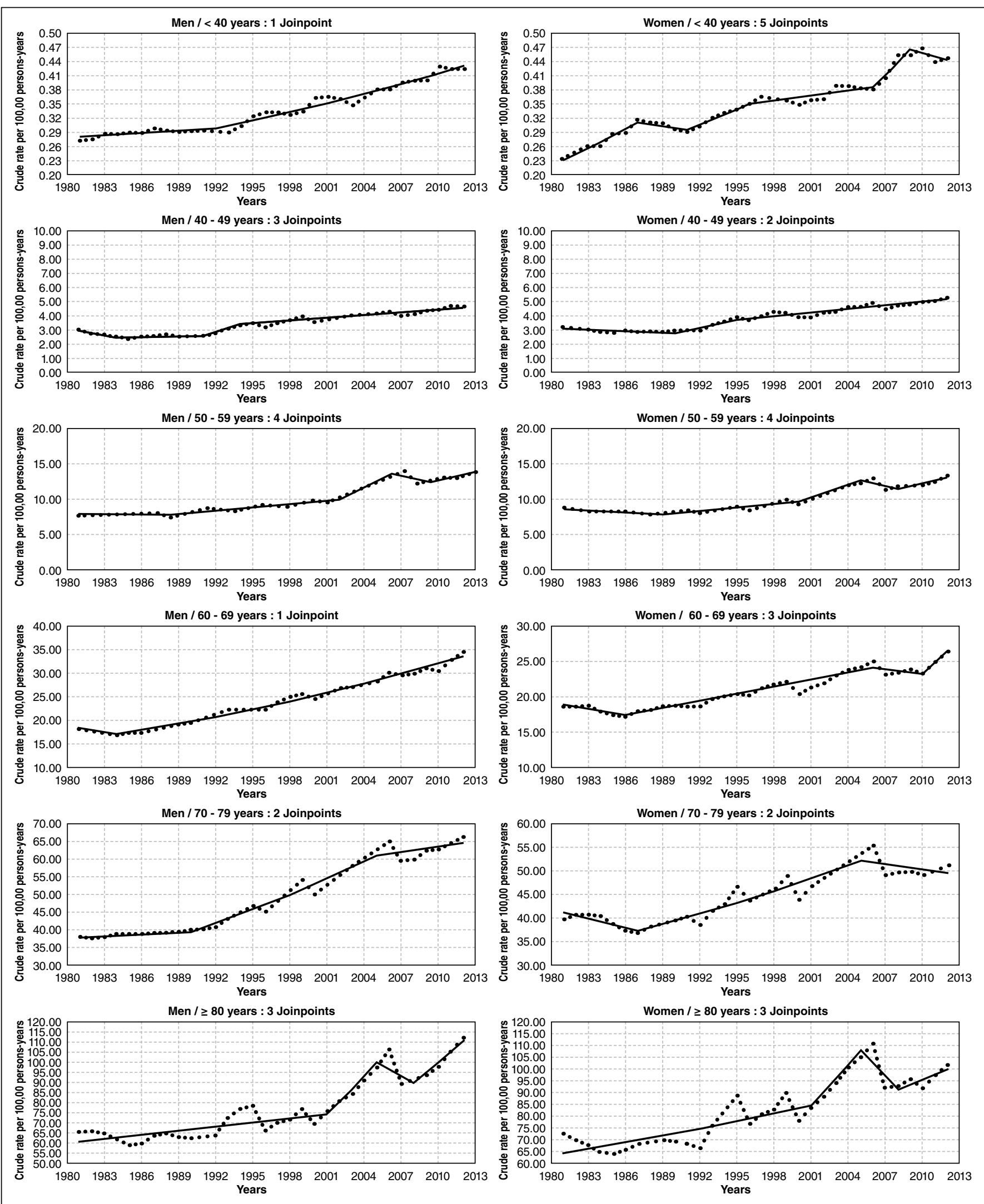

FIGURE 5. Age-specified colorectal cancer mortality rate per 100,000 person - year for Brazil according gender from 1981 to 2012. 


\section{DISCUSSION}

Several factors may have influenced the trends in the mortality rate, such as risk and protective factors, health care interventions, the changes in the classification of cancers, and the quality of mortality data among others ${ }^{(26)}$. Problems with the quality of mortality information in the first half of the study period may have affected the trends and the risk of death from CRC during this period. Improving the quality of the mortality information may have contributed to the less favorable performance trends, especially in the last 15 years; the deaths from CRC that were previously recorded in quality indicators began to be studied and considered as cases, thus increasing the frequency of total deaths from CRC. The introduction of the ICD 10th Edition in 1996 did not seem to have influenced the trends in the risk of death due to CRC, as little variation was observed in the mortality rates. Thus, the increased risk of death from CRC should be understood not only as an improvement in the quality of mortality information but also as a demonstration of the inadequate maintenance of healthy lifestyle behaviors combined with late diagnoses and inadequate treatment of the disease.

The trends in CRC mortality in Europe have been studied by several authors and published recently ${ }^{(22)}$. The authors of these studies concluded that the trends in CRC mortality were not significant in many European countries, although there were observed differences between western and eastern countries. These differences were related to a better awareness of the public regarding the disease, improved diagnosis and treatment of the disease and reductions in the prevalence of the disease.

A study conducted in Brazilian state capitals between 1980 and 1997 showed increased rates of mortality from CRC in all of them, although there were differences observed in the magnitude. Higher mortality rates were observed for men in the south and southeast, whose rate ratio reached values of 1.72 for the city of Florianópolis and 0.20 for the city of Manaus ${ }^{(19)}$, both in Brazil. Our findings indicated differences in the risk of death by sex when rates were analyzed by age group; we observed a higher risk of death among men aged 70 to 79 years after 1997 . The authors argue that this difference in the risk of death by gender and location is related to socioeconomic differences, lifestyles, access to health services, and quality of hospital care and prevention services.

The incidence and mortality trends of CRC among men and women aged 40 and older from 1969 to 1996 have been examined in Canada ${ }^{(10)}$. In that study, they observed that age-standardized mortality rates have decreased differently since 1969 for both men and women. They found an annual decrease in mortality of $0.45 \%$ from 1969 to 1985 and then of $1.33 \%$ from 1986 to 1996 . The decrease observed in the women was significantly higher in both in the 1969 to 1985 period and the 1986 to 1996 period, with AAPCs of $1.66 \%$ and $2.27 \%$, respectively. The authors indicated that although they could not prove the influence of screening for CRC, it is likely that this may have influenced the decline in the
CRC mortality rates. Furthermore, the difference between men and women in the rates of decline in mortality reflects the greater decrease in CRC incidence among women after 1985. It has been suggested that differences in exposure to risk factors such as diet and hormones may protect women from developing CRC. It is important to note that in our findings, the trends in older women have been stable for the previous decades, most likely because of different effects of the preventive strategies for different ages and sexes.

Another study analyzed cancer mortality trends in the Umbria region from 1978 to $2004^{(25)}$. The authors of that study observed non-significant trends in rates of CRC among women; however, they observed a constant increase in CRC rates among men (AAPC: $0.66 ; 95 \%$ CI: $0.28 ; 0.97)$. These unfavorable trends were similar to our results for men but differed from our findings for women. These trends were associated with a number of societal changes, preventive efforts and improvements in treatment. Moreover, the authors argued that the introduction of population-based screening interventions for CRC in 2006 would most likely contribute to continuing the downward trends in mortality over the next years.

In Japan, a joinpoint regression model was used to analyze the long-term trends in mortality from 1958 to $2004^{(23)}$ and found a favorable trend in risk of colon cancer for both men (APC: $-1.23 ; P<0.05$ ) and women (APC: $-0.52 ; P<0.05$ ) in the early ' 90 s. They also observed a favorable trend in the risk of rectum cancer in men over the same period as our study; however, in women, this trend was observed in the early 1970s, which differed from our results. The authors proposed that the increased consumption of meat from the 1940s to the 1970s in Japan may have represented the major driver of the increasing trend in CRC until the 1990s. Furthermore, increases in alcohol consumption, obesity rate and declines in physical activity may also have accounted for some of the increase in CRC among men.

The increase in CRC mortality trends observed in the last three decades in both sexes in Brazil contrasts with the trends observed in most European countries ${ }^{(2,3)}$. In these studies, were observed a decline of $2.0 \%$ per year in the mortality rates from 1997 to 2007. In another study, a favorable trend in CRC mortality in Spanish women between 1980 and 2007 was reported, demonstrating a significant APC of $1.4 \%{ }^{(4)}$. The declining trends observed by these authors were more favorable in the younger age groups, which is different from the findings of our study, as we found declining trends in the older women.

From 1975 to 2006 in the USA, there has been a significant decline in CRC mortality rates for both sexes and racial/ ethnic populations ${ }^{(8)}$. The authors of the USA study reported AAPC values for men and women of $-2.9 \%$ and $-2.7 \%$, respectively. When considering only the last five years, these values rise to $-3.9 \%$ and $-3.4 \%$ for men and women, respectively. According to the same author, the CRC mortality rate in the USA declined for both men and women in most racial and ethnic groups ${ }^{(7)}$. The author argued that these favorable trends were consistent with progress in cancer control efforts 
and reflected a combination of primary prevention and risk factor reduction as well as a contribution from screening and improved treatments.

Finally, data published in 2009 demonstrated variations in CRC mortality worldwide. The authors studied trends in age-standardized death rates in a single calendar year for select countries. They noted that while CRC mortality rates have declined in many economically developed countries, they continue to increase in some developing countries in South America and in Eastern Europe. This unfavorable trend results from increases in risk factors associated with "westernization" such as obesity and physical inactivity(5).

\section{CONCLUSION}

The data analyzed showed a significant improvement in the quality of data from Brazil's mortality information system in both sexes and across age groups. During the study period, there was an increase in the risk of death from CRC, and this increase was greater in men in the last 15 years. The AAPC between 1981 and 2012 showed a significant and growing trend in all of the age groups; this trend was maintained for men and women, with the exception of women in the elderly age group.

Preventive strategies, such as early detection and reducing exposure to known risk factors, may have different effects in men and women. The reason for this difference remains unclear, but it has been suggested that differences in exposure to risk factors such as diet and hormones may protect women from developing colorectal cancer. In addition to the increasing prevalence of obesity and the decreasing rates of physical activity, the elderly likely continue to contribute to the growing international CRC burden. The burden from the ageing population is expected to become an even greater public health problem worldwide and will challenge both healthcare institutions and healthcare professionals. Thus, it is important to improve screening in the developing world, to increase primary prevention actions reducing risk factors such as obesity, smoking and physical inactivity, and finally, to improve the technical capacity of health professionals involved in the care of cancer patients. By understanding sexand gender-related biological and socio-cultural differences in the risk of CRC, gender-specific strategies for screening, treatment and prevention protocols can be established to reduce the mortality and improve the quality of life.

\section{ACKNOWLEDGEMENTS}

This work was conducted with contribution from Pró Reitoria de Pesquisa, Criação e Inovação of the Universidade Federal da Bahia, Brazil.

\section{Authors' contributions}

Oliveira RC was responsible for study conception, performed data extraction, data checking, statistical analyses, and writing the first draft of the paper and contributed to the final draft of the paper. Rêgo MAV was responsible for supervision of research, statistical analyses, drafting the paper, and contributions to the final draft and contributed to the final draft of the paper.

Oliveira RC, Rêgo MAV. Risco de mortalidade por câncer colorretal no Brasil entre 1980 e 2013. Arq Gastroenterol. 2016,53(2): 76-83.

RESUMO - Contexto - O câncer colorretal é um dos cânceres mais comuns em todo o mundo, e a variação em suas taxas de mortalidade indica a importância de fatores ambientais em sua ocorrência. Enquanto os estudos de tendência têm indicado redução nas taxas de mortalidade por câncer colorretal na maioria dos países desenvolvidos, as mesmas tendências não foram observadas nos países em desenvolvimento. Além disso, o comportamento das tendências pode ser diferente quando analisado por idade e sexo. Objetivo - O presente estudo teve como objetivo analisar as tendências no risco de morte por câncer colorretal no Brasil com base no sexo e na faixa etária. Métodos - Registros de óbitos foram obtidos do Sistema de Informação sobre Mortalidade do Ministério da Saúde. O risco de morte e a variação percentual anual média (VPAM) das taxas de mortalidade foram calculados usando análise de tendências joinpoint no período de 1980 a 2013 . Todos os testes estatísticos foram bicaudais e utilizando um nível de significância de 5\%. Resultados - A razão da taxa (RT) foi estatisticamente maior nas idades de 70 a 79 para os homens (RT: 1,37; IC 95\%: 1,26; 1,49) em comparação com as mulheres (RT: 1,14; IC 95\%: 1,06; 1,24). Aumentos na variação percentual anual média foram observados em ambos os sexos. Embora os homens apresentassem maiores mudanças por cento (VPAM: 1,8; IC 95\%: 1,1; 2,6) em comparação com as mulheres (VPAM: 1,2; IC 95\%: 0,4;2,0), esta diferença não foi estatisticamente significativa. Tendências de crescimento nas taxas de mortalidade ocorreram em todas as faixas etárias, exceto para em mulheres com idade superior a 70 anos. Conclusão - Diferentemente da Europa e dos EUA, o Brasil tem mostrado um aumento nas taxas de mortalidade por câncer colorretal nas últimas três décadas; no entanto, as tendências mais favoráveis foram observadas em mulheres com mais de 70 anos de idade. A promoção de estilos de vida mais saudáveis, além de diagnóstico precoce e tratamento adequado, devem orientar as políticas de saúde pública visando reduções na morbimortalidade por câncer colorretal.

DESCRITORES - Neoplasias colorretais, mortalidade. Estudos de séries temporais. Vigilância da população. Distribuição por idade. Países em desenvolvimento. Políticas públicas de saúde. 


\section{REFERENCES}

1. Bishehsari F, Mahdavinia M, Vacca M, Malekzadeh R, Mariani-Costantini R. Epidemiological transition of colorectal cancer in developing countries: Environmental factors, molecular pathways, and opportunities for prevention. World $\mathrm{J}$ Gastroenterol. 2014;20:6055-72.

2. Bosetti C, Levi F, Rosato V, Bertuccio P, Lucchini F, Negri E, La Vecchia C. Recent trends in colorectal cancer mortality in Europe. Int J Cancer. 2011;129:180-91.

3. Bosetti C, Bertuccio P, Levi F, Lucchini F, Negri E, La Vecchia C. Cancer mortality in the European Union, 1970-2003, with a joinpoint analysis. Ann Oncol. 2008;19:631-40.

4. Cabanes A, Vidal E, Aragone N, Perez-Gomez, Pollán M, Lope V, Abente L. Cancer mortality trends in Spain: 1980-2007. Ann Oncol. 2010;21:14-20.

5. Center MM, Jemal A, Smith RA, Ward E. Worldwide variations in colorectal cancer. CA Cancer J Clin. 2009;59:366-78.

6. Coleman MP, Esteve J, Damiecki P, Arslan A, Renard H. Trends in Cancer Incidence and Mortality. IARC Scientific Publications. Lyon France; 1993;121, p. $225-56$.

7. Edwards BK, Noone AM, Mariotto AB, Simard EP, Boscoe FP, Henley J, et al. Annual Report to the Nation on the Status of Cancer, 1975-2010, Featuring Prevalence of Comorbidity and Impact on Survival Among Persons With Lung, Colorectal, Breast, or Prostate Cancer. Cancer;2014;1290-314.

8. Edwards BK, Ward E, Kohler BA, Eheman C, Zauber AG, Anderson RN, et al. Annual Report to the Nation on the Status of Cancer, 1975-2006, Featuring Colorectal Cancer Trends and Impact of Interventions (Risk Factors, Screening, and Treatment) to reduce Future Rates. Cancer. 2010;116:544-73.

9. Epidat. Programa para análise epidemiológica de dados. Versão 4.1, outubro 2014. Consellería de santidade, Xunta de Galicia, Espanha; Organização Panamericana de Saúde. Universidade CES, Colômbia. [Internet]. [Acessed 2015 June]. Available from: http://dxsp.sergas.es.

10. Gibbons L, Waters C, Mao Y, Ellison L. Trends in colorectal cancer incidence and mortality. Statistics in Canada. Health Reports. 2001;12:41-55.

11. Gili M, Cabanillas JL, Béjar L. Mortalidad evitable y cáncer de colon y reto. Gac Sanit. 2007;21:176-78.

12. Haggar FA, Boushey RP. Colorectal Cancer Epidemiology: Incidence, Mortality, Survival, and Risk Factors. Clin Colon Rectal Surg. 2009;22:191-7

13. Instituto Brasileiro de Geografia e Estatística. Brasília: IBGE; 2010. [Internet]. [Acessed 2015 July]. Available from http://www.ibge.gov.br
14. Instituto Nacional do Câncer. Estatísticas do Câncer: Vigilância do câncer e fatores de risco. [Internet]. [Acessed 2015 July]. Available from: http:// http:// www1.inca.gov.br/vigilancia.

15. International Agency for Cancer Research. GLOBOCAN 2012: section of cancer information. [Internet]. [Acessed 2015 July]. Available from: http://globocan.iarc. $\mathrm{fr} /$ factsheets/cancers/colorectal.asp.

16. Marrett LD. User documentation for surveillance Analytic Software: Joinpoint Cancer Care Ontario 2009. [Internet]. [Acessed 2015 June 2015]. Available from: http://www.cancerview.ca.

17. Mortality Information System. Departamento de Informática do Sistema Único de Saúde (DATASUS). [Internet]. [Acessed 2015 July]. Available from: http:// www2.datasus.gov.br.

18. National Cancer Institute. Joinpoint Regression Program, Version 4.2.0.1 - May 2015; Statistical Methodology and Applications Branch and Data Modeling Branch, Surveillance Research Program National Cancer Institute.

19. Neves FJ, Mattos IE, Koifman RJ. Mortalidade por câncer de cólon e reto nas capitais brasileiras no período de 1980-1997. Arq Gastroenterol. 2005;42:63-70.

20. Organização Mundial da Saúde. Classificação Estatística Internacional de Doenças. $9^{a}$ Revisão. São Paulo: Centro Brasileiro de Classificação de Doenças em Português; 1985. [Internet]. [Acessed 2015 July]. Available from: http://www. datasus.gov.br.

21. Organização Mundial da Saúde. Classificação Estatística Internacional de Doenças e Problemas Relacionados à Saúde. 10a Revisão. São Paulo: Centro Colaborador da OMS para a Classificação de Doenças em Português; 1995. [Internet] [Acessed July 2015]. Available from: http://www.datasus.gov.br.

22. Ouakrim DA, Pizot C, Boniol M, Malvezzi M, Boniol M, Negri E, et al. Trends in colorectal cancer mortality in Europe: resptrospective analysis of the WHO moratlity database. BMJ. 2015;351:h4970.

23. Qiu D, Katanoda K, Marugame T, Sobue T. A Joinpoint regression analysis of long-term trends in cancer mortality in Japan (1958-2004). Int J Cancer. 2009;124:443-8.

24. Siegel RL, Miller KD, Jemal A. Cancer Statistics, 2015. Ca Cancer J Clin. 2015;65:5-29.

25. Stracci F, Canosa A, Minelli L, Petrinelli AM, Cassetti T, Ramagnoli C, La Rosa F. Cancer mortality trends in the Umbria region of Italy 1978-2004: a joinpoint regression analysis. BMC Cancer. 2007,7:10.

26. Yang L, Fujimoto J, Qiu D, Sajamoto N. Trends in cancer mortality in the elderly in Japan, 1970-2007. Annals of Oncology. 2010;21:389-96. 